\title{
Mechanisms of atrial fibrillation in athletes: what we know and what we do not know
}

\author{
E. Guasch ${ }^{1}$ (D) $\cdot$ L. Mont ${ }^{1} \cdot$ M. Sitges ${ }^{1}$
}

Published online: 6 February 2018

(c) The Author(s) 2018. This article is an open access publication.

\begin{abstract}
Exercise is an emerging cause of atrial fibrillation (AF) in young individuals without coexisting cardiovascular risk factors. The causes of exercise-induced atrial fibrillation remain largely unknown, and conclusions are jeopardised by apparently conflicting data. Some components of the athlete's heart are known to be arrhythmogenic in other settings. Bradycardia, atrial dilatation and, possibly, atrial premature beats are therefore biologically plausible contributors to exercise-induced AF. Challenging findings in an animal model suggest that exercise might also prompt the development of atrial fibrosis, possibly due to cumulative minor structural damage after each exercise bout. However, there is very limited, indirect data supporting this hypothesis in athletes. Age, sex, the presence of comorbidities and cardiovascular risk factors, and genetic individual variability might serve to flag those athletes who are at the higher risk of exercise-induced AF. In this review, we will critically address current knowledge on the mechanisms of exercise-induced AF.
\end{abstract}

Keywords Atrial fibrillation $\cdot$ Endurance $\cdot$ Exercise $\cdot$ Atrial fibrosis $\cdot$ Vagal tone

\section{Introduction}

Atrial fibrillation (AF) is the most frequent sustained arrhythmia in the developed world, bearing a poor quality of life and increasing the risk of stroke and mortality. Prevalence of AF has been steadily increasing in recent years, and the number of individuals with $\mathrm{AF}$ is expected to double by 2060 [1]. The main factors promoting AF are ageing, structural heart disease, hypertension and diabetes, but these are absent in up to $15 \%$ of $\mathrm{AF}$ patients. The cause of $\mathrm{AF}$ in these young patients with no cardiovascular conditions has been the focus of extensive research in recent years, and obstructive sleep apnoea, obesity, tall stature and genetic predisposition have all been associated with increased risk of $\mathrm{AF}[2,3]$.

Reports published at the end of the 1990's suggested that veteran athletes are also at a higher-than-expected risk of $\mathrm{AF}[4,5]$. Subsequent small [6] and large epidemiological studies including $>1$ million individuals [7] confirmed this association. Endurance training is now a well-accepted

E. Guasch

eguasch@clinic.cat

1 Institut Clinic Cardiovascular, Hospital Clínic de Barcelona; IDIBAPS; Universitat de Barcelona; CIBERCV., 08036 Barcelona, Catalonia, Spain cause of AF [8]. Heavily trained athletes are, on average, at a 3-8-fold increased risk of AF [5, 6] and its prevalence is as high as $15 \%$ in veteran elite athletes $[9,10]$. Intense physical activity history is reported by up to $60 \%$ of young patients with $\mathrm{AF}$ in the absence of any cardiopulmonary disease [2]. In the daily practice, exercise-induced AF is usually diagnosed in middle-aged males who have been practicing very intense endurance sports (e.g., marathon running [6], cycling [10], cross-country skiing [11]) in the long-term ( $>10$ years) [12]. Not uncommonly, AF is diagnosed some years after regular training has been discontinued [6]. Overall, these data challenge the notion that the benefits of physical activity have no appreciable limits [13].

The emergence of exercise as a potential cause of AF is relatively novel, and its pathology and underlying mechanisms remain largely unknown. Few works have shed some light on the causes of exercise-induced AF, and uncertainties are still prevailing in this field. Is AF only a marker of extreme physical adaptation or is it associated with a pathological substrate? If so, do we have any evidence in humans of a deleterious effect of physical activity on cardiac structures? Why does the healthy exercise become harmful? Do illicit performance-enhancing substances play a role? While clinical and epidemiological evidence for exercise-induced $\mathrm{AF}$ is compelling, there is little evidence for a deleterious effect in the left ventricle: why do these cardiac chambers behave so differently? And, finally, why do only a few 
KEY MESSAGE

- Middle-aged males who have been engaged in strenuous endurance training for more than 10 years and who are otherwise healthy, are at the highest risk of developing AF caused by exercise.

- Vagal enhancement, atrial dilation and, possibly, atrial myocardial fibrosis are likely contributors to exercise-induced AF, but definitive evidence in athletes is still warranted.

- Atrial fibrosis in athletes might be the consequence of increased atrial stretch, inflammation and oxidative stress during strenuous exercise, that incompletely recover between bouts.

- Large knowledge gaps in the mechanisms of exercise-induced AF impedes providing evidence-based directives aiming at improving primary prevention or treatment of AF specifically in athletes.

athletes develop AF? In this review, these issues will be critically reviewed on the basis of current evidence.

\section{Is exercise-induced AF an extreme form of physiological adaptation?}

Our knowledge of the substrate that sustains AF in athletes is poor, largely speculative, based on general notions of $\mathrm{AF}$ pathology and, in few cases, derived from clinically relevant animal models. In the classic and simple, but useful, Coumel's triangle, an appropriate substrate, a predisposing modulator and a timely trigger are needed in variable proportions to initiate and maintain AF (Fig. 1). The currently available evidence for the potential contribution of each of these mechanisms in exercise-induced $\mathrm{AF}$ is summarised in Tab. 1. Interestingly, some of the classical components of the physiologic cardiac adaptation to regular physical activity (so-called athlete's heart) have also been associated to AF pathology.
On the one hand, atrial size is a well-recognised independent predictor of incident AF [14]. In experimental models, dilatation of the left atrium facilitates the instauration and perpetuation of AF even in the absence of myocardial fibrosis [15]. We still do not fully understand the mechanisms behind AF promotion in dilated atria, but disparities on conduction velocity throughout the left atrium probably contribute [15]. Conduction heterogeneity in dilated atria might be originated by cellular electrophysiological changes occurring at cellular level in hypertrophied cardiomyocytes [16]. Moreover, atrial dilatation increases the atrial critical mass and facilitates the establishment of re-entrant electrical activity and $\mathrm{AF}$ [17]. On the other hand, atrial dilatation is a hallmark of the athlete's heart [18]. Atrial dilatation results from the adaptation of the atria to regular training: both atria enlarge to accommodate the increased cardiac output requirements during exercise. However, the characteristics of atrial dilatation are not exhaustively known. It is currently unknown whether atrial dilation geometry differs in athletes and in patients with a heart disease. Notably, at a similar degree of atrial dilatation, atrial function seems to

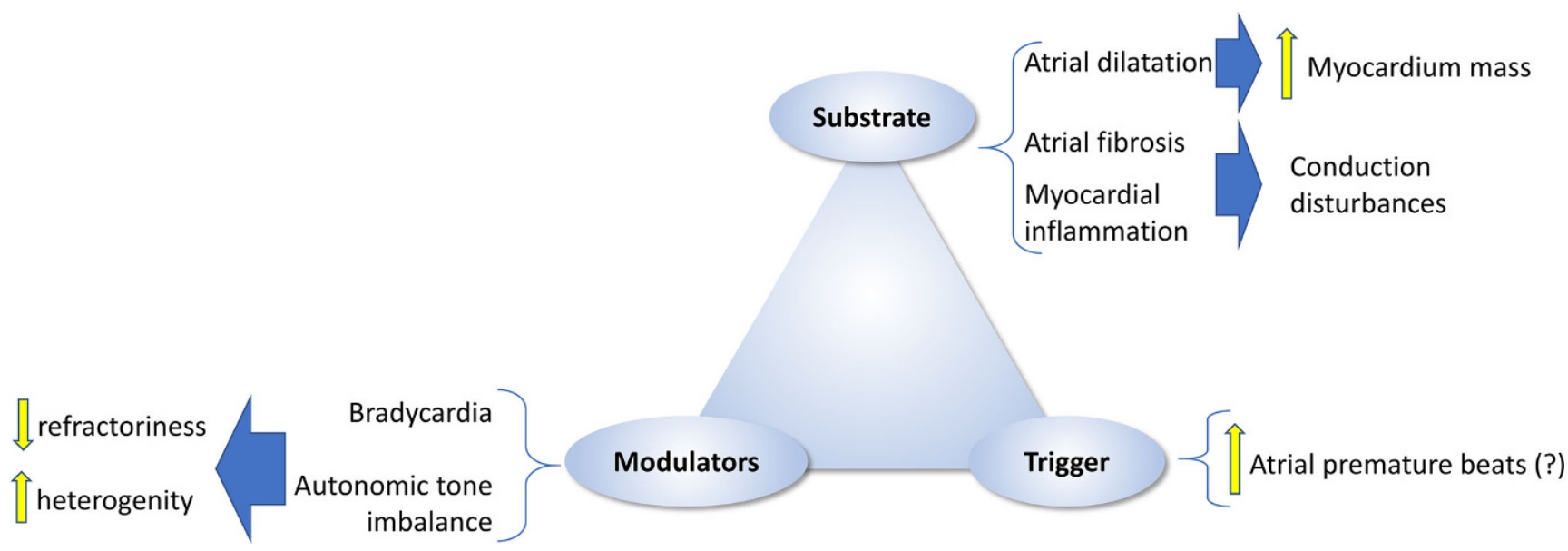

Fig. 1 Schematic representation of the potential mechanisms underlying exercise-induced atrial fibrillation represented in a Coumel's triangle of arrhythmogenesis, and their functional consequences 
Table 1 Evidence in animal models and in athletes supporting the potential mechanisms underlying exercise-induced atrial fibrillation

\begin{tabular}{|c|c|c|c|}
\hline & Evidence in animal models & Evidence in humans & Main knowledge gaps \\
\hline \multirow[t]{2}{*}{ Atrial dilatation } & \multirow[t]{2}{*}{$\begin{array}{l}\text { Atrial dilatation occurs in heavily } \\
\text { trained animals [20] }\end{array}$} & $\begin{array}{l}\text { Atrial dilatation increases with exer- } \\
\text { cise-load in athletes [18] }\end{array}$ & \multirow{2}{*}{$\begin{array}{l}\text { It is unclear whether atrial dilatation } \\
\text { geometry is similar in athlete's heart } \\
\text { and in pathological settings }\end{array}$} \\
\hline & & $\begin{array}{l}\text { A subgroup of athletes may be at } \\
\text { risk of high atrial wall stress during } \\
\text { exercise [65] }\end{array}$ & \\
\hline \multirow[t]{2}{*}{ Atrial fibrosis } & $\begin{array}{l}\text { Histological evidence of exercise-in- } \\
\text { duced atrial fibrosis }[20,31]\end{array}$ & $\begin{array}{l}\text { Fibrosis-related biomarkers are in- } \\
\text { creased in athletes [33-36] }\end{array}$ & $\begin{array}{l}\text { Direct evidence of exercise-induced } \\
\text { fibrosis in athletes is lacking }\end{array}$ \\
\hline & $\begin{array}{l}\text { Atrial fibrosis is central in exer- } \\
\text { cise-induced AF [31] }\end{array}$ & Prolonged $p$-wave duration $[18,43]$ & $\begin{array}{l}\text { Does increased wall stretch con- } \\
\text { tributes to myocardial fibrosis } \\
\text { pathology? }\end{array}$ \\
\hline Inflammation & $\begin{array}{l}\text { Local and systemic inflammation at } \\
\text { each exercise bout [56] }\end{array}$ & $\begin{array}{l}\text { Systemic exercise-load dependent } \\
\text { inflammation has been reported [ } 53 \text {, } \\
54]\end{array}$ & $\begin{array}{l}\text { Local myocardial inflammation is } \\
\text { uncertain in heavily trained athletes }\end{array}$ \\
\hline \multirow[t]{2}{*}{$\begin{array}{l}\text { Vagal enhancement } \\
\& \text { bradycardia }\end{array}$} & $\begin{array}{l}\text { Reduced intrinsic heart rate [24] and } \\
\text { vagal tone enhancement [20] have } \\
\text { been found }\end{array}$ & $\begin{array}{l}\text { Both vagal tone enhancement [18] } \\
\text { and intrinsic heart rate reduction [25] } \\
\text { are present in athletes }\end{array}$ & $\begin{array}{l}\text { Whether parasympathetic tone con- } \\
\text { tributes to AF in athletes has not } \\
\text { been demonstrated }\end{array}$ \\
\hline & $\begin{array}{l}\text { Vagal enhancement governs AF } \\
\text { inducibility [20] }\end{array}$ & $\begin{array}{l}\text { Most AF episodes in athletes occur in } \\
\text { vagal settings [4] }\end{array}$ & $\begin{array}{l}\text { Could parasympathetic tone be } \\
\text { a therapeutic target? }\end{array}$ \\
\hline \multirow[t]{2}{*}{$\begin{array}{l}\text { Atrial premature } \\
\text { beats }\end{array}$} & $\begin{array}{l}\text { Increased pulmonary vein stretch } \\
\text { may increase arrhythmogenicity [85] }\end{array}$ & $\begin{array}{l}\text { Mild }[18,29] \text { or no }[10] \text { increase in } \\
\text { atrial premature beats in athletes }\end{array}$ & $\begin{array}{l}\text { Current evidence shows no } \\
\text { contribution to exercise-induced AF }\end{array}$ \\
\hline & $\begin{array}{l}\text { No evidence for an increase in atrial } \\
\text { premature beats/triggered activity in } \\
\text { heavily trained animals }[20,31]\end{array}$ & & \\
\hline
\end{tabular}

$A F$ atrial fibrillation

be preserved in athletes, but not in patients with a structural heart disease [19].

A slow heart rate is a common finding in well-trained individuals. For decades, bradycardia in athletes has been attributed to an imbalance in autonomic tone characterised by parasympathetic tone enhancement and sympathetic tone withdrawal. Parasympathetic tone shortens the atrial refractory period and thereby facilitates re-entry and AF. Results in an animal model suggest that exercise enhances parasympathetic tone partially through an increased cardiac sensitivity to acetylcholine, an effect mediated by downregulation of regulators of $\mathrm{G}$ protein signalling (RGS) [20]. In this model, parasympathetic enhancement was central in the early stages of exercise-induced AF pathology [20]. Notably, most AF relapses in athletes occur in vagally-dominant situations such as during sleep or after meals [4]. Remarkable clinical implications may derive if parasympathetic tone is confirmed as a main driver of exercise-induced AF. For example, antiarrhythmic drugs with vagolytic properties (e.g., dysopiramide [8, 21]) could be favoured over other options, and intracardiac autonomic ganglia could become a primary target in ablation procedures [22]. Conversely, adrenergic-mediated AF is less frequent in athletes [4]. Although the parasympathetic and sympathetic tone shorten atrial refractoriness to a similar extent, the more heterogeneous atrial parasympathetic innervation yields a larger arrhythmic susceptibility [23].
The notion that parasympathetic tone enhancement is the sole cause of bradycardia in athletes has recently been disputed. D'Souza et al. elegantly demonstrated in mice that a reduction in intrinsic heart rate (i.e., changes in the sinus node function independent of autonomic regulation) through HCN4 downregulation governs bradycardia in trained individuals [24], thereby supporting conclusions from previous studies in athletes [25]. Moreover, the modification of the intrinsic properties of the sinus node is consistent with reports pointing to a high prevalence of sinus node disease and pacemaker requirement in athletes [10]. The increased atrial refractoriness dispersion during bradycardia might indeed link intrinsic heart rate reduction to exercise-induced AF pathology [26].

It is likely that both autonomic tone-mediated remodelling and intrinsic heart rate-mediated remodelling contribute to bradycardia in athletes, and that the balance between both factors change with training intensity and/or sport discipline [27]. In the general population, either parasympathetic tone-driven bradycardia or intrinsic heart rate-driven, bradycardia is associated with a higher risk of AF [28].

In the general population, atrial premature beats may trigger AF events in the presence of other predisposing factors or, when very frequent, may be the main etiological factor. It has been postulated that endurance athletes present with a higher burden of atrial premature beats than sedentary individuals [18, 29]. Nevertheless, it remains unknown 
whether such a mild increase is enough to significantly contribute to the AF burden in athletes.

Both atrial enlargement and bradycardia are more evident in endurance sports athletes than in strength sports (e.g., weight-lifting) practitioners. In parallel, exercise-induced $\mathrm{AF}$ is far more frequent in endurance athletes. On this basis, some authors hypothesised that AF might be an extreme manifestation of the physiological athlete's heart. However, recent results from our and other groups disputed this notion. Works in animal models suggested that atrial fibrosis, a clearly pathological hallmark, could contribute to exercise-induced AF pathology. Atrial fibrosis disrupts normal electrical conduction in the atrium and, possibly, interferes with myocyte-fibroblast electrical coupling, thereby facilitating the establishment of re-entries and, eventually, $\mathrm{AF}$ [30]. In a rat model, we first found that a 16-week intense training protocol increased AF inducibility in an electrophysiological test. In addition to atrial dilatation and an enhanced parasympathetic tone, we observed increased atrial interstitial fibrosis [20], a finding that has been subsequently confirmed by others [31]. Of note, both studies found a modest $(\approx 60 \%)$ increase in atrial fibrosis [20, 31 , contrasting to much larger atrial fibrosis deposits in other pathologic settings known to be associated with AF, such as left ventricular dysfunction or valve disease. In these conditions, atrial fibrosis increases up to 500\% [32]. Although some experimental work suggests that exerciseinduced atrial fibrosis drives AF inducibility [31], it is also plausible that additional contributing factors should be present, at least in the early stages of exercise-induced AF.

\section{Do we have data on pathological remodelling in humans?}

The confirmation in humans of a pathologic substrate in intensively trained individuals is still pending. In particular, the need of invasive tests to assess atrial fibrosis hampers its confirmation in athletes. Atrial biopsies are an unrealistic approach to quantify myocardial fibrosis in apparently healthy individuals, and magnetic resonance techniques are still underdeveloped. Therefore, only indirect estimates are currently available.

Results on plasmatic biomarkers are consistent with the presence of a profibrotic state in some trained individuals. Active or veteran athletes present with higher levels of profibrotic markers, such as galectin-3 [33], ST2 [34], certain circulating pro-fibrotic microRNAs such as mir-21 [35], and collagen turnover peptides PICP, CITP and TIMP-1 [36]. These plasmatic biomarkers have been associated with incident or recurrent AF in clinical works in the general population and in patients with structural heart disease [37-40].
It should be noted, though, that the interpretation of these results is complex and, at best, suggest the existence of a pro-fibrotic systemic environment that could favour atrial fibrosis.

Echocardiographic parameters such as atrial strain have been used as surrogate markers for the degree of atrial fibrosis in patients undergoing mitral valve surgery [41]. However, results in well-trained endurance athletes are conflicting $[42,43]$.

The ECG is an easy, widely available tool that may be useful to provide a rough approach to atrial structures. In patients with mitral valve disease, $p$-wave duration associates with atrial fibrosis and size [44, 45], and flags those individuals at an increased risk of AF. Endurance athletes present with an accumulated physical activity-dependent $p$ wave prolongation $[43,46]$. In football players, such a prolongation is independent of atrial size, and thereby fibrosis evolves as a plausible underlying substrate [47].

\section{What triggers pathological remodelling?}

Secondary prevention trials [48] and observational studies assessing incident AF in older individuals or in individuals with a high burden of cardiovascular risk factors [49-51] demonstrate that low to moderate load of physical activity is safe and may even be antiarrhythmic. Conversely, a high exercise load may promote AF in some individuals. Overall, these findings depict a U-shaped relationship between exercise load and AF incidence [2, 12]. It is unclear which are the determinants promoting the transition from safe exercise to the appearance of exercise-induced atrial fibrillation. Chances are that atrial dilatation or bradycardia beyond a certain level in well-trained athletes facilitate AF. It is also possible, though speculative, that an increase in $\mathrm{AF}$ incidence associates with the establishment of atrial fibrosis.

In this regard, the mechanisms behind the potential instauration of atrial fibrosis remain unknown. Fig. 2 summarises the factors that have been postulated to contribute to exercise-induced atrial fibrosis. It is possible that systemic or mechanic insults during strenuous exercise bouts inflict cumulative microstructural myocardial damage. As for the right ventricle, it has been postulated that such damage develops after incomplete recovery between exercise bouts, thereby leading to permanent damage to the atria.

Pro-inflammatory insults and low-level inflammation have been associated with AF incidence in the general population [52]. Although regular physical activity has been demonstrated to yield a systemic chronic anti-inflammatory effect, each exercise bout disturbs the inflammatory balance and prompts a pro-inflammatory status. Intense exercise transiently increases neutrophil count and induces 


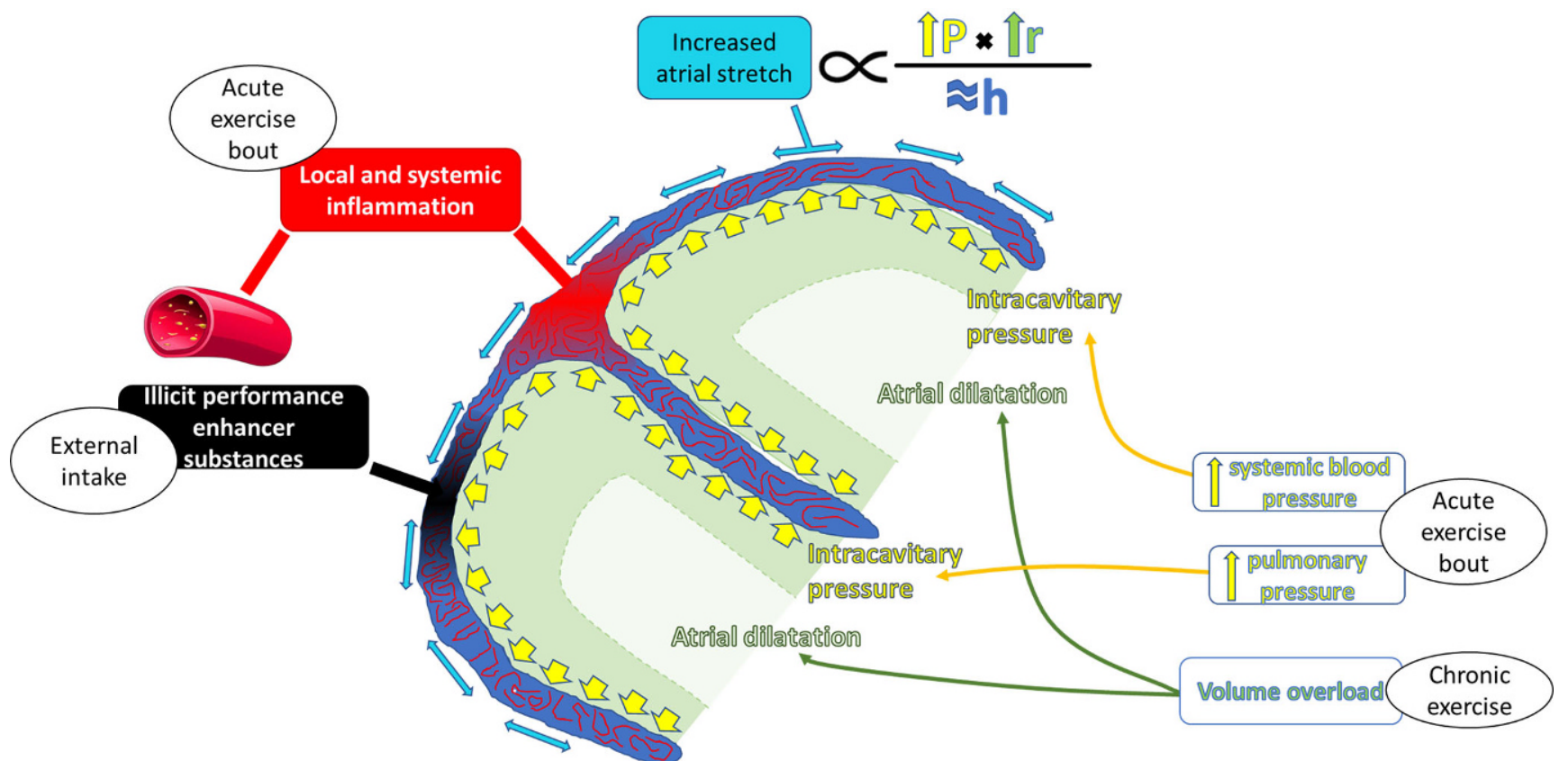

Fig. 2 Potential factors leading to a pathological atrial remodelling in athletes (atrial fibrosis). Systemic blood pressure and, particularly, pulmonary pressure promote an increase in atrial intracavitary pressure during exercise. In the presence of chronically dilated atria and limited ability to increase wall thickness, atrial wall stretch has remarkably increased, which may promote the activation of profibrotic mechanisms. A pro-inflammatory status during each exercise bout and intake of an illicit performance enhancer may also contribute. $R A$ right atrium, $L A$ left atrium

the release of pro-inflammatory cytokines such as interleukin-6, interleukin-8, C-reactive protein and ST2 [34, 53-55]. Systemic inflammation may locally extend to the myocardium. In a swimming-based animal model, extenuating exercise bouts were associated with myocardial leukocyte infiltration [56]. Interestingly, local inflammation mediated by stretch-activated tumour necrosis-alpha (TNFa) seems to be critical in exercise-induced atrial fibrosis pathology [31]. In humans, a transient p-wave prolongation after ultra-distance races was observed independently of atrial size, leading the authors to postulate that transient inflammatory infiltration or oedema could cause such conduction disturbances [57]. Changes in plasma of TNF$\alpha$ and interleukin-12p70 concentrations correlate to right ventricular dysfunction after ultra-distance races in welltrained athletes [54]. Oxidative stress, which has also been linked to an increased AF incidence [58], increases in a load-dependent way after exercise [59]. Several attempts have been undertaken to blunt the pro-inflammatory and oxidative status after strenuous exercise with nutritional supplements and drugs, yielding conflicting results on the systemic inflammatory status $[60,61]$, and showing no benefits on cardiac haemodynamic overload markers [62].

A transient increase of cardiac necrosis markers (e.g., troponin I and troponin $\mathrm{T}$ ) after long distance races was reported some years ago and claimed to be a marker of cardiac necrosis during exercise. Plasmatic troponin levels were associated with right, but not left, ventricular transient dysfunction after strenuous exercise [63], but a worse outcome in those athletes with repetitive troponin elevation has not been demonstrated. However, our current understanding of troponin release during long races involves a process of cardiomyocyte membrane permeabilisation rather than pathological ischaemia [64]. To date, repetitive myocardial ischaemia and necrosis cannot be established as a source of AF substrate.

Each exercise bout involves a volume overload that superimposes a mechanical stress to which the thin atrial wall is particularly sensitive. Wall stress positively correlates with intracavitary pressure and size, and inversely with wall thickness. Atrial enlargement implies that wall stress is higher, according to Laplace's law (Fig. 2). Additionally, if the curvature of the atria changes (i.e., becoming more elliptic), wall stress might also increase (the flatter the wall, the higher the wall stress) [65]. Atrial natriuretic peptide (ANP) levels, a marker of atrial stretch, is increased at rest in athletes in comparison with healthy individuals [66, 67]. Atrial pressure increases during exercise $[31,68]$, further increasing wall stretch and prompting a subsequent deleterious remodelling. Such deleterious effects might be particularly notorious in a subset of athletes with dilated and dysfunctional atria [69]. Increasing loads of physical activity are associated with an acute, dose-dependent transient atrial dysfunction, which becomes severe after very intense and prolonged bouts [70]. As aforementioned, increased atrial wall stress has been shown to trigger 
TNF-mediated activation of local inflammation, eventually leading to atrial fibrosis in an animal model [31]. Blocking TNF- $\alpha$ did prevent exercise-induced atrial fibrosis and inducibility. Speculatively, hidden hypertension or hypertension during exercise bouts may further exacerbate this increase in atrial wall stress and accelerate it [71]. Overall, increased atrial wall stretch appears as an attractive trigger for pathological remodelling after strenuous exercise, but definitive proof remains elusive.

\section{What makes the atrium different, why is it selectively affected?}

For a long time, research in sports cardiology focussed on the study of left ventricle adaptation to variable amounts of physical activity. It was convincingly demonstrated that left ventricle adaptation to high loads of physical activity does not usually convey pathological stigmas. Proteomic studies emphasised the physiological remodelling of the left ventricle in intensively-trained animals [72], and some studies suggest that physical activity may even protect against ventricular arrhythmias [73, 74]. However, the atria and right ventricle were scarcely studied.

The recent demonstration of potentially deleterious effects of very high doses of physical activity has moved the focus towards the atria and the right ventricle [12]. The physiological remodelling of the left ventricle contrasts with the identification of atrial and right ventricular arrhythmias in athletes. Morphological, functional and molecular differences between left ventricle, right ventricle and both atria underlie a distinct response to high levels of physical activity [75].

As described in the previous section, the morphology of the atrium makes it particularly vulnerable to haemodynamic disturbances. Haemodynamic overload promotes atrial dilatation and, subsequently, increases wall stretch. Conversely, the ability of the left ventricle to respond to repetitive mechanical overload by thickening its myocardial walls enables the left ventricle to maintain wall stretch within a non-deleterious range $[75,76]$. This adds to differences in the cellular and molecular characterisation of atria and ventricles. Indeed, atrial fibroblasts show an enhanced reactivity to pathological stimuli in comparison with ventricular fibroblasts [77], resulting in a remarkably larger atrial than ventricular fibrosis burden upon the instauration of non-ischaemic heart failure in animal models [78].

Altogether, clinical outcomes, morphological characteristics and fibroblast reactivity data suggest that the atria have a greater sensitivity to the haemodynamic overload than the left ventricle, potentially justifying that the atria are primarily affected by the deleterious consequences of strenuous physical activity [12].

\section{Are performance-enhancing drugs a plausible explanation for exercise-induced AF?}

Performance-enhancing drugs have been postulated to contribute to AF burden in athletes. Nevertheless, the obscure nature of doping hinders any robust conclusion and thereby this issue remains, at best, speculative. Available data from athletes who have been banned from competition suggest that the most commonly used substances in high-level endurance-trained athletes who aim to improve their performance are erythropoietin (EPO), anabolic-androgenic steroids (AAS), and stimulant and sympathomimetic drugs.

Erythropoietin and its derivatives increase erythrocyte synthesis and oxygen supply to peripheral muscle, evolving as a tempting drug for endurance athletes. To date, however, there is no data reporting $\mathrm{AF}$ as a significant side effect of EPO.

The use of AAS has been associated with AF in isolated case reports [79]. A study with body-builders recently demonstrated that chronic anabolic steroid administration associates with a prolonged atrial electromechanical delay [80]. Atrial electromechanical delay predicts new-onset AF, likely reflecting underlying substrate abnormalities [81].

Sympathomimetic drugs, such as ephedrine and amphetamine derivates, are used as stimulants and might trigger AF; a specific form of apoptosis in myocardial biopsies termed eosinophilic bands has been associated with ephedrine intake [82].

Nevertheless, we should note that the use of performance-enhancing substances is not exclusive for long-distance endurance sports. Rather, their use is also relatively common in bodybuilders and weight-lifters, although no reports demonstrating an increased risk of AF in these cohorts

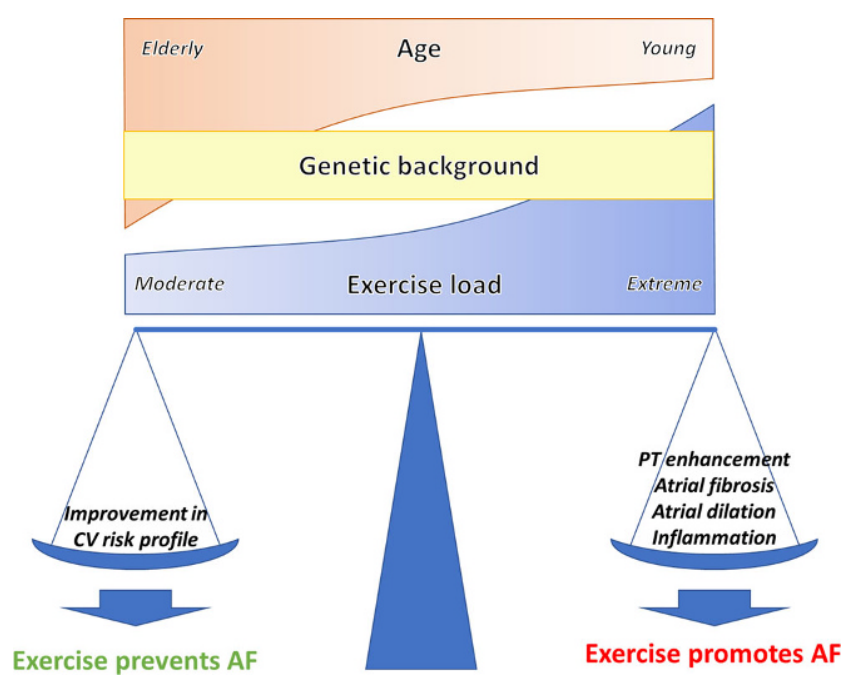

Fig. 3 Representation of the factors contributing to the balance between the antiarrhythmic and the pro-arrhythmic effect of exercise 


\title{
Advertisement placed here.
}

\author{
SCS bohn \\ stafleu \\ CL van loghum \\ Springer Media
}

Houten 2018 


\title{
Advertisement placed here.
}

\author{
SCS bohn \\ stafleu \\ CL van loghum \\ Springer Media
}

Houten 2018 


\title{
Advertisement placed here.
}

\author{
SCS bohn \\ stafleu \\ CL van loghum \\ Springer Media
}

Houten 2018 


\title{
Advertisement placed here.
}

\author{
SCS bohn \\ stafleu \\ CL van loghum \\ Springer Media
}

Houten 2018 
has been published. It should be acknowledged, though, that it is biologically plausible that the effect of performanceenhancing substances is boosted in those endurance athletes in whom both a larger chamber dilatation/fibrosis and parasympathetic tone enhancement occur.

\section{Why do only few athletes develop AF?}

While exercise is performed by a large part of the population, only some athletes will develop AF. Moreover, some individuals may get protected by exercise from AF, as aforementioned [48-51]. Fig. 3 summarises the potential factors involved in this complex relationship. In terms of AF incidence, the arrhythmogenicity of exercise likely results from the net balance between its beneficial (e.g., improvement of risk factors burden) and its potentially pro-arrhythmic (e.g., atrial fibrosis) effects; age and the presence of cardiovascular risk factors modulate this relationship [12]. Elderly individuals accruing several cardiovascular risk factors may benefit from exercise [51]. Conversely, middle-aged individuals without cardiovascular risk factors may be more prone to exercise-induced AF [7].

On top of these factors, it is evident that some degree of genetically-derived interindividual variability facilitates the development of a pathological remodelling or enhance athlete's heart features [69]. Men are apparently at a higher risk, likely because of bigger atria and a more extensive remodelling as compared with women [42]. Nevertheless, longer follow-up in contemporaneous cohorts of women is warranted [83]. The presence of certain genetic mutations or polymorphisms may put some athletes at a higher risk. A mutation in a subunit of the $\mathrm{IK}_{\mathrm{s}}$ potassium channel has been shown to confer an increased sensitivity to atrial stretch and could therefore facilitate AF during hypertension or in athletes [84]. Unfortunately, to date, there are insufficient data that reliably identify those athletes who are at risk of exercise-induced AF.

\section{Conclusions}

The higher incidence of AF in athletes is now well-accepted, but its causes remain elusive. Atrial dilatation and parasympathetic enhancement are likely contributors. Some data in animals suggest that extreme physical activity associates with a pathological remodelling involving atrial fibrosis. Transient inflammation and an increase in atrial wall stress, associated with uncomplete recovery between exercise bouts, could trigger the development of atrial fibrosis. Nevertheless, confirmation in humans is still waiting, largely due to limitations in registries and histological confirmation. On the other hand, the contribution of performance-enhancing substances does not appear to be remarkable. Overall, data are still insufficient to adopt specific prevention and diagnostic or prognostic strategies in the clinical setting. With our current knowledge, the potential risk of AF should not be used to limit the amount of physical activity.

Funding This manuscript was partially supported by grants from the Instituto de Salud Carlos III (PI13/01580, PI16/00703); Ministerio de Economia y Competitividad (SAF2015-64136R); CERCA programme/Generalitat de Catalunya; European Union's Horizon2020 research and innovation programme under grant agreement $n^{\circ} 633196$ (CATCH-ME); and Centro de Investigación Biomédica en RED (CIBERCV 16/11/00354).

Conflict of interest E. Guasch, L. Mont and M. Sitges declare that they have no competing interests.

Open Access This article is distributed under the terms of the Creative Commons Attribution 4.0 International License (http:// creativecommons.org/licenses/by/4.0/), which permits unrestricted use, distribution, and reproduction in any medium, provided you give appropriate credit to the original author(s) and the source, provide a link to the Creative Commons license, and indicate if changes were made.

\section{References}

1. Krijthe BP, Kunst A, Benjamin EJ, et al. Projections on the number of individuals with atrial fibrillation in the European Union, from 2000 to 2060. Eur Heart J. 2013;34:2746-51.

2. Calvo N, Ramos P, Montserrat S, et al. Emerging risk factors and the dose-response relationship between physical activity and lone atrial fibrillation: a prospective case-control study. Europace. 2016;18:57-63.

3. Gudbjartsson DF, Arnar DO, Helgadottir A, et al. Variants conferring risk of atrial fibrillation on chromosome $4 \mathrm{q} 25$. Nature. 2007;448:353-7.

4. Mont L, Sambola A, Brugada J, et al. Long-lasting sport practice and lone atrial fibrillation. Eur Heart J. 2002;23:477-82.

5. Karjalainen J, Kujala UM, Kaprio J, Sarna S, Viitasalo M. Lone atrial fibrillation in vigorously exercising middle aged men: casecontrol study. BMJ. 1998;316:1784-5.

6. Molina L, Mont L, Marrugat J, et al. Long-term endurance sport practice increases the incidence of lone atrial fibrillation in men: a follow-up study. Europace. 2008;10:618-23.

7. Andersen K, Rasmussen F, Held C, Neovius M, Tynelius P, Sundström J. Exercise capacity and muscle strength and risk of vascular disease and arrhythmia in 1.1 million young Swedish men: cohort study. BMJ. 2015;351:h4543.

8. Kirchhof P, Benussi S, Kotecha D, et al. ESC guidelines for the management of atrial fibrillation developed in collaboration with EACTS. Eur Heart J. 2016;37:2893-962.

9. Grimsmo J, Grundvold I, Maehlum S, Arnesen H. High prevalence of atrial fibrillation in long-term endurance cross-country skiers: echocardiographic findings and possible predictors-a 28-30 years follow-up study. Eur J Cardiovasc Prev Rehabil. 2010;17:100-5.

10. Baldesberger S, Bauersfeld U, Candinas R, et al. Sinus node disease and arrhythmias in the long-term follow-up of former professional cyclists. Eur Heart J. 2008;29:71-8.

11. Andersen K, Farahmand B, Ahlbom A, et al. Risk of arrhythmias in 52755 long-distance cross-country skiers: a cohort study. Eur Heart J. 2013;34:3624-31. 
12. Guasch E, Mont L. Diagnosis, pathophysiology, and management of exercise-induced arrhythmias. Nat Rev Cardiol. 2017;14:88-101.

13. Eckel RH, Jakicic JM, Ard JD, et al. AHA/ACC guideline on lifestyle management to reduce cardiovascular rsk: a report of the American College of Cardiology/American Heart Association Task Force on practice guidelines. J Am Coll Cardiol. 2013;63:2960-84.

14. Vaziri SM, Larson MG, Benjamin EJ, Levy D. Echocardiographic predictors of nonrheumatic atrial fibrillation. The Framingham Heart Study. Circulation. 1994;89:724-30.

15. Neuberger H-R, Schotten U, Blaauw Y, et al. Chronic atrial dilatation, electrical remodeling, and atrial fibrillation in the goat. J Am Coll Cardiol. 2006;47:644-53.

16. Spach MS, Heidlage JF, Dolber PC, Barr RC. Electrophysiological effects of remodeling cardiac gap junctions and cell size: experimental and model studies of normal cardiac growth. Circ Res. 2000;86:302-11.

17. Zou R, Kneller J, Leon LJ, Nattel S. Substrate size as a determinant of fibrillatory activity maintenance in a mathematical model of canine atrium. Am J Physiol Heart Circ Physiol. 2005;289:H1002-H12.

18. Wilhelm M, Roten L, Tanner H, Wilhelm I, Schmid J-P, Saner H. Atrial remodeling, autonomic tone, and lifetime training hours in nonelite athletes. Am J Cardiol. 2011;108:580-5.

19. Gabrielli L, Enríquez A, Córdova S, Yáñez F, Godoy I, Corbalán R. Assessment of left atrial function in hypertrophic cardiomyopathy and athlete's heart: a left atrial myocardial deformation study. Echocardiography. 2012;29:943-9.

20. Guasch E, Benito B, Qi X, et al. Atrial fibrillation promotion by endurance exercise: demonstration and mechanistic exploration in an animal model. J Am Coll Cardiol. 2013;62:68-77.

21. Boucher M, Chassaing C, Herbet A, Duchêne-Marullaz P. Interactions with the cardiac cholinergic system: effects of disopyramide and its mono-N-dealkylated metabolite. Life Sci. 1992;50:PL161PL6.

22. Verma A, Saliba WI, Lakkireddy D, et al. Vagal responses induced by endocardial left atrial autonomic ganglion stimulation before and after pulmonary vein antrum isolation for atrial fibrillation. Heart Rhythm. 2007;4:1177-82.

23. Liu L, Nattel S. Differing sympathetic and vagal effects on atrial fibrillation in dogs: role of refractoriness heterogeneity. Am J Physiol Heart Circ Physiol. 1997;273(2 Pt 2):H805-H16.

24. D'Souza A, Bucchi A, Johnsen AB, et al. Exercise training reduces resting heart rate via downregulation of the funny channel HCN4. Nat Commun. 2014;5:3775.

25. Katona PG, McLean M, Dighton DH, Guz A. Sympathetic and parasympathetic cardiac control in athletes and nonathletes at rest. J Appl Physiol. 1982;52:1652-7.

26. Luck JC, Engel TR. Dispersion of atrial refractoriness in patients with sinus node dysfunction. Circulation. 1979;60:404-12.

27. Azevedo LF, Perlingeiro PS, Hachul DT, et al. Sport modality affects bradycardia level and its mechanisms of control in professional athletes. Int J Sports Med. 2014;35:954-9.

28. Skov MW, Bachmann TN, Rasmussen PV, et al. Association between heart rate at rest and incident atrial fibrillation (from the Copenhagen Electrocardiographic Study). Am J Cardiol. 2016;118:708-13.

29. Talan DA, Bauernfeind RA, Ashley WW, Kanakis C, Rosen KM. Twenty-four hour continuous ECG recordings in long-distance runners. Chest. 1982;82:19-24.

30. Burstein B, Nattel S. Atrial fibrosis: mechanisms and clinical relevance in atrial fibrillation. J Am Coll Cardiol. 2008;51:802-9.

31. Aschar-Sobbi R, Izaddoustdar F, Korogyi AS, et al. Increased atrial arrhythmia susceptibility induced by intense endurance exercise in mice requires TNFa. Nat Commun. 2015;6:6018.

32. Cardin S, Guasch E, Luo X, et al. Role for microRNA-21 in atrial profibrillatory fibrotic remodeling associated with experi- mental postinfarction heart failure. Circ Arrhythm Electrophysiol. 2012;5:1027-35.

33. Hättasch R, Spethmann S, de Boer RA, et al. Galectin-3 increase in endurance athletes. Eur J Prev Cardiol. 2014;21:1192-9.

34. Roca E, Nescolarde L, Lupón J, et al. The dynamics of cardiovascular biomarkers in non-elite marathon runners. J Cardiovasc Transl Res. 2017;10:206-8.

35. Baggish AL, Hale A, Weiner RB, et al. Dynamic regulation of circulating microRNA during acute exhaustive exercise and sustained aerobic exercise training. J Physiol. 2011;589:3983-94.

36. Lindsay MM, Dunn FG. Biochemical evidence of myocardial fibrosis in veteran endurance athletes. Br J Sports Med. 2007;41:447-52.

37. Nortamo S, Ukkola O, Lepojärvi S, et al. Association of sST2 and hs-CRP levels with new-onset atrial fibrillation in coronary artery disease. Int J Cardiol. 2017;248:173-8.

38. Fashanu OE, Norby FL, Aguilar D, et al. Galectin-3 and incidence of atrial fibrillation: the Atherosclerosis Risk in Communities (ARIC) study. Am Heart J. 2017;192:19-25.

39. Swartz MF, Fink GW, Sarwar MF, et al. Elevated pre-operative serum peptides for collagen I and III synthesis result in post-surgical atrial fibrillation. J Am Coll Cardiol. 2012;60:1799-806.

40. McManus DD, Tanriverdi K, Lin H, et al. Plasma microRNAs are associated with atrial fibrillation and change after catheter ablation (the miRhythm study). Heart Rhythm. 2015;12:3-10.

41. Cameli M, Lisi M, Righini FM, et al. Usefulness of atrial deformation analysis to predict left atrial fibrosis and endocardial thickness in patients undergoing mitral valve operations for severe mitral regurgitation secondary to mitral valve prolapse. Am J Cardiol. 2013;111:595-601.

42. Sanchis L, Sanz-De La Garza M, Bijnens B, et al. Gender influence on the adaptation of atrial performance to training. Eur J Sport Sci. 2017;1391:1-7.

43. Brugger N, Krause R, Carlen F, et al. Effect of lifetime endurance training on left atrial mechanical function and on the risk of atrial fibrillation. Int J Cardiol. 2014;170:419-25.

44. Scott CC, Leier CV, Kilman JW, Vasko JS, Unverferth DV. The effect of left atrial histology and dimension on $\mathrm{P}$ wave morphology. J Electrocardiol. 1983;16:363-6.

45. Win TT, Venkatesh BA, Volpe GJ, et al. Associations of electrocardiographic P-wave characteristics with left atrial function, and diffuse left ventricular fibrosis defined by cardiac magnetic resonance: the PRIMERI study. Heart Rhythm. 2015;12:155-62.

46. Wilhelm M, Roten L, Tanner H, Schmid J-P, Wilhelm I, Saner $\mathrm{H}$. Long-term cardiac remodeling and arrhythmias in nonelite marathon runners. Am J Cardiol. 2012;110:129-35.

47. Petersson R, Berge HM, Gjerdalen GF, et al. P-wave morphology is unaffected by atrial size: a study in healthy athletes. Ann Noninvasive Electrocardiol. 2014;19:366-73.

48. Malmo V, Nes BM, Amundsen BH, et al. Aerobic interval training reduces the burden of atrial fibrillation in the short term: a randomized trial. Circulation. 2016;133:466-73.

49. Qureshi WT, Alirhayim Z, Blaha MJ, et al. Cardiorespiratory fitness and risk of incident atrial fibrillation: results from the Henry ford exercise testing (FIT) project. Circulation. 2015;131:1827-34.

50. Bapat A, Zhang Y, Post WS, et al. Relation of physical activity and incident atrial fibrillation (from the Multi-Ethnic Study of Atherosclerosis). Am J Cardiol. 2015;116:883-8.

51. Mozaffarian D, Furberg CD, Psaty BM, Siscovick D. Physical activity and incidence of atrial fibrillation in older adults: the cardiovascular health study. Circulation. 2008;118:800-7.

52. Guo Y, Lip GYH, Apostolakis S. Inflammation in atrial fibrillation. J Am Coll Cardiol. 2012;60:2263-70.

53. Kasapis C, Thompson PD. The effects of physical activity on serum C-reactive protein and inflammatory markers: a systematic review. J Am Coll Cardiol. 2005;45:1563-9. 
54. La Gerche A, Inder WJ, Roberts TJ, Brosnan MJ, Heidbuchel H, Prior DL. Relationship between inflammatory cytokines and indices of cardiac dysfunction following intense endurance exercise. PLoS ONE. 2015;10:1-15.

55. Bekos C, Zimmermann M, Unger L, et al. Non-professional marathon running: RAGE axis and ST2 family changes in relation to open-window effect, inflammation and renal function. Sci Rep. 2016;6:32315.

56. Oláh A, Németh BT, Mátyás C, et al. Cardiac effects of acute exhaustive exercise in a rat model. Int J Cardiol. 2015;182:258-66.

57. Wilhelm M, Zueger T, De Marchi S, et al. Inflammation and atrial remodeling after a mountain marathon. Scand J Med Sci Sports. 2014;24:519-25.

58. Tahhan AS, Sandesara PB, Hayek SS, et al. Association between oxidative stress and atrial fibrillation. Heart Rhythm. 2017;98: 1615-6.

59. Hattori N, Hayashi T, Nakachi K, et al. Changes of ROS during a two-day ultra-marathon race. Int J Sports Med. 2009;30:426-9.

60. Grabs V, Kersten A, Haller B, et al. Rutoside and hydrolytic enzymes do not attenuate marathon-induced inflammation. Med Sci Sports Exerc. 2017;49:387-95.

61. McAnulty SR, Owens JT, McAnulty LS, et al. Ibuprofen use during extreme exercise: effects on oxidative stress and PGE2. Med Sci Sports Exerc. 2007;39:1075-9.

62. Clauss S, Scherr J, Hanley A, et al. Impact of polyphenols on physiological stress and cardiac burden in marathon runners-results from a substudy of the BeMaGIC study. Appl Physiol Nutr Metab. 2017;42:523-8.

63. La Gerche A, Burns AT, Mooney DJ, et al. Exercise-induced right ventricular dysfunction and structural remodelling in endurance athletes. Eur Heart J. 2012;33:998-1006.

64. Eijsvogels TMH, Fernandez AB, Thompson PD. Are there deleterious cardiac effects of acute and chronic endurance exercise? Physiol Rev. 2016;96:99-125.

65. Gabrielli L, Bijnens BH, Butakoff C, et al. Atrial functional and geometrical remodeling in highly trained male athletes: for better or worse? Eur J Appl Physiol. 2014;114:1143-52.

66. Rogers PJ, Tyce GM, Bailey KR, Bove AA. Exercise-induced increases in atrial natriuretic factor are attenuated by endurance training. J Am Coll Cardiol. 1991;18:1236-41.

67. Date H, Imamura T, Onitsuka H, et al. Differential increase in natriuretic peptides in elite dynamic and static athletes. Circ J. 2003;67:691-6.

68. Reeves JT, Groves BM, Cymerman A, et al. Operation everest II: cardiac filling pressures during cycle exercise at sea level. Respir Physiol. 1990;80:147-54.

69. Gabrielli L, Bijnens BH, Brambila C, et al. Differential atrial performance at rest and exercise in athletes: potential trigger for developing atrial dysfunction? Scand J Med Sci Sports. 2016;26:1444-54.

70. Sanz-de_PARTICLESPACE_la Garza M, Grazioli G, Bijnens $\mathrm{BH}$, et al. Acute, exercise dose-dependent impairment in atrial performance during an endurance race: $2 \mathrm{D}$ ultrasound speckletracking strain analysis. Jacc Cardiovasc Imaging. 2016;9:1380-8.

71. Leischik R, Spelsberg N, Niggemann H, Dworrak B, Tiroch K. Exercise-induced arterial hypertension—an independent factor for hypertrophy and a ticking clock for cardiac fatigue or atrial fibrillation in athletes? F1000Res. 2014;3:105.

72. Dantas PS, Sakata MM, Perez JD, et al. Unraveling the role of high-intensity resistance training on left ventricle proteome: is there a shift towards maladaptation? Life Sci. 2016;152:156-64.

73. Ejlersen H, Andersen ZJ, von Euler-Chelpin MC, Johansen PP, Schnohr P, Prescott E. Prognostic impact of physical activity prior to myocardial infarction: case fatality and subsequent risk of heart failure and death. Eur J Prev Cardiol. 2017;24(10):1112-9.

74. Dor-Haim H, Lotan C, Horowitz M, Swissa M. Intensive exercise training improves cardiac electrical stability in myocardialinfarcted rats. J Am Heart Assoc. 2017;6:e5989.

75. Sanz-de la Garza M, Rubies C, Batlle M, et al. Severity of structural and functional right ventricular remodeling depends on training load in an experimental model of endurance exercise. Am J Physiol Heart Circ Physiol. 2017;3:H459-H68.

76. La Gerche A, Heidbüchel H, Burns AT, et al. Disproportionate exercise load and remodeling of the athlete's right ventricle. Med Sci Sports Exerc. 2011;43:974-81.

77. Burstein B, Libby E, Calderone A, Nattel S. Differential behaviors of atrial versus ventricular fibroblasts: a potential role for plateletderived growth factor in atrial-ventricular remodeling differences. Circulation. 2008;117:1630-41.

78. Hanna N, Cardin S, Leung T-K, Nattel S. Differences in atrial versus ventricular remodeling in dogs with ventricular tachypacinginduced congestive heart failure. Cardiovasc Res. 2004;63:236-44.

79. Lau DH, Stiles MK, John B, Shashidhar YGD, Sanders P. Atrial fibrillation and anabolic steroid abuse. Int J Cardiol. 2007;117:e86-e7.

80. Akçakoyun M, Alizade E, Gündoğdu R, et al. Long-term anabolic androgenic steroid use is associated with increased atrial electromechanical delay in male bodybuilders. Biomed Res Int. 2014;2014:45152

81. De Vos CB, Weijs B, Crijns HJGM, et al. Atrial tissue Doppler imaging for prediction of new-onset atrial fibrillation. Heart. 2009;95:835-40.

82. Casella M, Dello Russo A, Izzo G, et al. Ventricular arrhythmias induced by long-term use of ephedrine in two competitive athletes. Heart Vessels. 2015;30:280-3.

83. Guasch E, Mont L. Exercise, sex and atrial fibrillation: arrhythmogenesis beyond Y-chromosome? Heart. 2015;101:1607-9.

84. Otway R, Vandenberg JI, Guo G, et al. Stretch-sensitive KCNQ1 mutation. A link between genetic and environmental factors in the pathogenesis of atrial fibrillation? J Am Coll Cardiol. 2007;49:578-86.

85. Chang S-L, Chen Y-C, Chen Y-J, et al. Mechanoelectrical feedback regulates the arrhythmogenic activity of pulmonary veins. Heart. 2007;93:82-8. 